\title{
Tradução, adaptação e validação do Servant Leadership Questionnaire (Escala de Liderança Servidora)
}

Translation, adaptation, and validation of Servant Leadership Questionnaire Traducción, adaptación y validación del Servant Leadership Questionnaire (Escala de Liderazgo Servidor)

\author{
Saulo Pereira de ALMEIDA ${ }^{1}$ \\ André FARO \\ Universidade Federal de Sergipe, São Cristóvão, SE, Brasil
}

ReSUMO Este estudo objetivou traduzir e validar o Servant Leadership Questionnaire (SLQ) buscando adaptar a Escala de Liderança Servidora (ELSE) para o português brasileiro. Empreendeu-se um estudo psicométrico com 337 participantes (alunos e servidores da Universidade Federal de Sergipe, maiores de 18 anos), que possuíssem chefe imediato. Utilizou-se um questionário sociodemográfico, a SLQ (traduzida e adaptada neste estudo), a Escala de Satisfação com o Trabalho (EST) e uma escala de liderança transformacional. Realizaram-se análises descritivas e, para a validade fatorial da ELSE, utilizou-se a Análise Fatorial Exploratória (PAF, rotação Promax), além da avaliação da confiabilidade ( $\alpha$ ). Para a validade convergente empregou-se a correlação de Pearson $(r)$ e para a validade preditiva utilizou-se a regressão linear (stepwise). A análise de dados realizou-se no Statistical Package for the Social Science (v.19). A solução final apresentou 3 fatores, totalizando 47,7\% de variância explicada: (a) influência visionária ( $\alpha=0,87$; 9 itens), (b) abnegação( $\alpha=0,88$; 9 itens), e (c) intendência organizacional ( $\alpha=0,83 ; 5$ itens). Constatou-se a validade convergente da ELSE, que apresentou correlações moderadas e significativas com a liderança transformacional. A validade preditiva também foi confirmada, visto que as dimensões da ELSE explicaram 48\% da variância explicada da satisfação com a chefia. As limitações do estudo relacionam-se à falta de grupos comparáveis e à amostragem não probabilística. Sugere-se, para pesquisas futuras, a investigação da estrutura fatorial confirmatória e aplicações empíricas da ELSE.

Palavras-chave:

Liderança; estudos de validação; psicometria.

Abstract This study aimed to translate and validate the Servant Leadership Questionnaire (SLQ) seeking to adapt the Escala de Liderança Servidora (ELSE) for Brazilian Portuguese. A psychometric study was conducted with 337 participants (students and employees of the Federal University of Sergipe, over 18 years of age), who had an immediate boss. The study used a sociodemographic questionnaire, the SLQ (translated and adapted in this study), the Escala de Satisfação no Trabalbo (EST) [Work Satisfaction Scale], and a transformational leadership scale. Descriptive analyses were done, and for the factor validity of the ELSE, the Exploratory Factor Analysis (PAF, Promax rotation) was used, in addition to reliability testing $(\alpha)$. For convergent validity, the Pearson correlation $(r)$ was used, and for predictive validity, (stepwise) linear regression. Data analysis was performed using Statistical Package for the Social Science (v.19). The final solution presented three factors, totaling $47.7 \%$ of explained variance: (a) visionary influence ( $\alpha=.87 ; 9$ items), (b) abnegation ( $\alpha=.88 ; 9$ items), and (c) organizational stewardship ( $\alpha=.83 ; 5$ items). The convergent validity of the $E L S E$ was determined, which showed moderate and significant correlations with transformational leadership. Predictive validity was also confirmed, since the dimensions of the new scale accounted for $48 \%$ of the explained variance of satisfaction with the leader. Limitations of this study relate to the lack of comparable groups and non-probabilistic sampling. It is suggested that future research investigate the confirmatory factor structure and empirical applications of the ELSE. Keywords:

Leadership; validation studies; psychometrics. 
Resumen El presente estudio tuvo como objetivo traducir y validar el Servant Leadership Questionnaire (SLQ) con vistas a adaptar la Escala de Liderazgo Servidor (ELSE) para el portugués de Brasil. Fue realizado un estudio psicométrico con 337 individuos mayores de 18 años (estudiantes y funcionarios de la Universidade Federal de Sergipe), que tuviesen un jefe inmediato. Se utilizó un cuestionario sociodemográfico, la SLQ (traducida y adaptada al estudio), la Escala de Satisfação no Trabalho (EST) y una escala de liderazgo transformacional. Fueron realizados análisis descriptivos y, para la validez factorial de la ELSE, se utilizó el Análisis Factorial Exploratorio (PAF, rotación Promax) y la evaluación de la fiabilidad $(\alpha)$. Para la validez convergente, se utilizó la correlación de Pearson ( $r$ y para la validez predictiva, se utilizó la regresión lineal (stepwise). Los dados fueron analizados con el SPSS (v.19). La solución final obtuvo 3 factores, representando el 47,7\% de la varianza explicada: (a) influencia visionaria ( $\alpha=0,87 ; 9$ ítems), (b) abnegación ( $\alpha=0,88 ; 9$ ítems), y (c) custodia organizacional ( $\mathrm{a}=0,83 ; 5$ ítems). Se comprobó la validez convergente de la ELSE, que presentó correlaciones moderadas y significativas con el liderazgo transformacional. la validez predcitiva también fue confirmada, puesto que las dimensiones de la ELSE explicaron el 48\% de la varianza aclarada respecto de la satisfacción con el jefe. Las limitaciones de este estudio se refieren a la falta de grupos comparables y al muestreo no probabilístico. Con vista a investigaciones futuras, se sugiere estudios acerca de la estructura factorial confirmatoria y aplicaciones empíricas de la ELSE.

Palabras-clave:

Liderazgo; estudios de validación; psicometría.

A

liderança se configura como um dos temas mais investigados na área do comportamento organizacional. Embora seja um fenômeno que desperte interesse de diversas áreas e possua inúmeras abordagens (dos traços, comportamental, contingencial e carismática) que propõem como sua estrutura e funcionamento se desenvolvem, novos resultados continuam a surgir e questionamentos sobre a melhor forma de liderar ainda perduram.

Em revisão realizada por Yukl e Van Fleet (1992) e recentemente por Avolio, Walumbwa e Weber (2009), destaca-se que as definições de liderança são um tanto arbitrárias e isso está relacionado a controvérsias das abordagens, em que algumas consideram, e outras não, fatores como variáveis organizacionais e culturais (House \& Aditya, 1997), comportamentos expressos pelo líder e ênfase na execução das tarefas ou na otimização dos relacionamentos (Bass, 1990). Tais controvérsias costumam ocasionar confusões e divergências, dificultando o desenvolvimento e a propagação de novas descobertas.

Quanto à definição, Yukl e Van Fleet (1992) entendem liderança como um processo que envolve influência nos objetivos, tarefas e ações de um grupo, visando implementar estratégias e alcançar objetivos. Os autores assinalam ainda que o processo de influência impacta na manutenção e identificação do grupo com a cultura organizacional. De acordo com Hayden (2011), a liderança é compreendida como o processo pelo qual uma pessoa influencia sua equipe de trabalho a fim de cumprir suas metas e atividades. Por outro lado, Greenleaf (1977), com sua visão mais filosófica, afirma que um líder é visto essencialmente como um servo, dedicado aos indivíduos e grupos que pretende liderar. Tal visão e definição do líder diz respeito à liderança servidora, teoria desenvolvida por Robert Greenleaf nos anos 1970. Em sua essência, a teoria retorna aos paradigmas da abordagem dos traços de liderança, por estar centrada nas características do líder. No entanto, pelo papel desempenhado pelo líder servidor, sua responsabilidade moral e sua capacidade de inspirar pessoas, tal teoria se aproxima também da abordagem carismática.

Devido a desconfianças na capacitação dos gestores para gerenciar as relações com seus colaboradores, em meados dos anos 1980 e 1990, houve aumento do interesse na liderança servidora, a qual promove a criação do autointeresse dos líderes na busca de melhoria e desenvolvimento de seus liderados (Mittal \& Dorfman, 2012; Van Dierendonck, 2011).

Quanto aos pressupostos teóricos do construto, é possível observar preceitos do cristianismo e da filosofia, no que se refere a servir ao próximo (Greenleaf, 1970). Pode-se observar também termos psicológicos, como crescimento pessoal, autoconsciência e identificação, combinados com os conceitos de organização plana e visão compartilhada (Page \& Wong, 2000). A liderança servidora incorpora ainda ideais de emancipação, qualidade total, formação de equipes e gestão participativa, além da ética ao servir (Russel \& Stone, 2002). Neste panorama, Pousa (2014) e Van Dierendonck (2011) enfatizam em suas compilações, compostas pelas 
principais medidas do construto, a viabilidade de se investigar a liderança servidora, visto que os instrumentos possuem bons índices psicométricos.

Como afirma Spears (2010), essa teoria da liderança enfatiza o "aumento da servidão aos outros. É uma abordagem holística para o trabalho, promovendo um senso de comunidade e partilha do poder na tomada de decisão" (p. 3). De acordo com Greenleaf (1970, 1977), para ser um líder servidor qualificado, a pessoa deve buscar servir primeiro aos subordinados. Porém, tais conceituações não são facilmente operacionalizadas.

No intuito de construir medidas para a avaliação das características pertinentes à liderança, critérios como validade, fidedignidade, parcimônia e possibilidade de generalização são comumente almejados (Bass, 1990). Tal realidade não foi diferente no desenvolvimento da liderança servidora, que, a partir da década de 1980, devido à semelhança com outras teorias da área, necessitou passar por análises fatoriais não só a fim de constatar a estrutura fatorial e fidedignidade dos instrumentos criados, como também para posicioná-la adequadamente no conjunto de instrumentos de liderança existentes (Barbuto \& Wheeler, 2006; Pousa, 2014).

Nessa época, a liderança servidora passou a ser comparada à teoria da troca líder-membro, formulada em 1976 por George Graen, e à liderança transformacional, aprimorada por Bernard Bass, em 1985, devido a semelhanças existentes em aspectos como o papel do líder e as relações interpessoais e grupais. No entanto, recentemente, Liden, Wayne, Zhao e Henderson (2008) conseguiram destacar diferenças entre as três teorias tanto nos aspectos citados quanto no papel do liderado e no componente moral (específico da liderança servidora), além de nos resultados esperados e nas relações a nível organizacional, mostrando-se pertinente o interesse, na época, de operacionalizar a teoria (Mittal \& Dorfman, 2012).

Para fins de análises fatoriais, a semelhança entre a liderança servidora, a liderança transformacional e a teoria da troca líder-membro gerou a possibilidade de utilizá-las para uma validação convergente (Barbuto \& Wheeler, 2006). Além disso, como a liderança servidora é antecedente da satisfação no trabalho, autores como Choudhary, Akhtar e Zaheer (2013), Ehrhart (2004) e Van Dierendonck (2011) sustentam que tal construto pode ser utilizado para a realização da validade preditiva das medidas de liderança servidora.

Tais constatações foram feitas a partir de instrumentos que se pautaram, assim como este estudo, no primeiro e mais utilizado, segundo Pousa (2014), modelo teórico da área, proposto por Spears (1995), autor influente por ter sido aluno de Robert Greenleaf. Spears buscou representar a liderança servidora de acordo com os trabalhos de Greenleaf (1970, 1977), traduzindo-a em 10 atributos distintos e inter-relacionados: ouvir (enfatizar a importância da comunicação ao identificar o interesse das pessoas); empatia (esforçar-se para entender e simpatizar com os demais); cura (auxiliar emocionalmente os liderados, garantindo integridade); consciência (auxiliar no entendimento das questões que envolvem ética, poder e valores); persuasão (influenciar a partir de argumentos e não pelo poder posicional); conceituação (capacidade visionária, poder pensar além das atividades operacionais); previsão (assimilar lições do passado e ponderar prováveis consequências no futuro das decisões atuais); intendência (garantir credibilidade ao servir às necessidades dos outros); crescimento das pessoas (reconhecer a responsabilidade de promover o crescimento profissional dos colaboradores); e construção da sociedade (criar relações saudáveis entre a organização e a sociedade). É válido dizer que, após diversos estudos empíricos, Spears (2010) enfatiza novamente as 10 dimensões, dando maior peso ao modelo teórico.

O modelo de Spears (1995) serviu de suporte teórico para as principais medidas validadas do construto como a de Ehrhart (2004), Laub (1999) e Liden et al. (2008), inclusive para a Servant Leadership Questionnaire (SLQ), de Barbuto e Wheeler (2006) - todas produzidas nos Estados Unidos. Vale ressaltar que a nível nacional praticamente não existem estudos que explorem a liderança servidora (Costa, 2007; Diamante \& Grahl, 2012; Germano \& Sá, 2013; Martins, Rosa, Silva, \& Bustos, 2012; Viegas, 2009). Considerando a busca no scielo.org, por exemplo, com os seguintes descritores: scale, servant, servant leadership, theoretical model, escala $\mathrm{e}$ liderança servidora, não houve resultado. Com isso, busca-se com este estudo preencher uma lacuna quanto ao desenvolvimento da teoria no Brasil a partir da disponibilização de um instrumento a fim de incentivar a investigação empírica do construto.

Além disso, considerando que comportamentos para a atuação do líder podem ser aprimorados, busca-se também contribuir com a atuação de gestores, tanto na procura de melhores relações interpessoais como no desenvolvimento da satisfação, do comprometimento, da cidadania organizacional e do desempenho dos subordinados (Avolio et al., 2009; Bambale, Shamsudin, \& Subramaniam, 2012; Barbuto \& Wheeler, 2006; Chan \& Mak, 2015; Choudhary et al., 2013; Morris, 2013). A partir do desenvolvimento de uma nova 
medida, especificamente para o Brasil, pode-se implementar programas de treinamento a fim de desenvolver competências do líder servidor.

No Brasil, o termo "servidor" não é de simples compreensão, considerando a natureza da liderança servidora, pois o termo representa isoladamente a ideia de servir. Porém, segundo Weiszflog (2012), quem o pratica seriam serventes ou domésticos. A ideia do termo estaria associada também à servidão, que na língua portuguesa relaciona-se à condição de servo ou escravo (Weiszflog, 2012). No entanto, o significado da palavra no contexto organizacional para líderes refere-se à noção de abnegação e dedicação, em que há um comportamento altruísta em prol dos que atuam na instituição.

A partir desse panorama, este estudo objetivou traduzir, adaptar e validar o SLQ para o português brasileiro, determinando as características psicométricas da nova Escala de Liderança Servidora (ELSE) em uma amostra brasileira. Para atestar a estrutura fatorial encontrada, realizou-se uma validação convergente entre as dimensões da liderança servidora e da liderança transformacional, além de uma validação preditiva entre as dimensões da liderança servidora e a satisfação com a chefia.

\section{MÉTODO}

\section{Participantes}

Este trabalho possui abordagem quantitativa e de corte transversal. A amostragem foi não probabilística por conveniência e os critérios de inclusão foram: (a) ser aluno (graduação ou pós-graduação), servidor efetivo ou terceirizado da Universidade Federal de Sergipe (exceto professores); (b) possuir mais de 18 anos; (c) ter chefe imediato; e (d) estar trabalhando com vínculo empregatício por no mínimo três meses na empresa atual.

A obrigação de pertencer à referida universidade se deu a fim de garantir a mínima homogeneidade da amostra, pois o fato de os alunos trabalharem em diversas organizações torna a amostra heterogênea, o que, segundo Laros (2005), é aconselhável para a análise fatorial, sendo realizado neste estudo. Já a exclusão dos professores da amostra ocorreu devido ao vínculo distanciado com a sua chefia imediata, apesar de, como qualquer profissional, terem metas a cumprir. Para maior controle da amostra, os alunos que atuavam como docentes foram excluídos. Os demais critérios referem-se ao contexto de trabalho, procurando excluir quem estava em período de experiência, estagiários, bolsistas e empreendedores. Além disso, foram excluídos questionários por invariância absoluta e ausência de respostas.

Responderam aos instrumentos 361 participantes, sendo que alguns foram eliminados por: (a) menos de três meses de trabalho (9 exclusões), (b) bolsistas ou estagiários (5 exclusões), (c) instrumentos incompletos (9 exclusões) e (d) invariância absoluta nas respostas (uma exclusão). Com isso, a amostra foi composta por 337 respondentes ( $93 \%$ válidos). Com relação ao cálculo amostral para realizar análises fatoriais, utilizou-se a regra de 10 sujeitos por variável a partir do principal instrumento do estudo (Pasquali, 1999), que possuía 23 itens. Ou seja, o ideal é que existissem 230 participantes válidos, número alcançado por este estudo.

Dos 337 participantes, 61,4\% ( $n=207)$ eram alunos da graduação e pós-graduação, 22,6\% ( $n=76)$ eram funcionários efetivos e 16\% ( $n=54)$ eram funcionários terceirizados; com maior incidência de mulheres (52,2\%; $n=176)$ e idades variando entre 19 e 62 anos $(M=29,58 ; D P=8,99)$. Quanto à renda individual mensal, houve variação entre $\mathrm{R} \$ 588,00$ e $\mathrm{R} \$ 13.000,00(M=2052,46 ; D P=1937,62)$; o tempo de trabalho na organização variou entre 3 meses e 40 anos $(M=4,51 ; D P=6,61)$; e o tempo de trabalho com o atual chefe variou entre 3 meses e 20 anos $(M=2,1 ; D P=2,57)$. Com relação à escolaridade, $61,1 \%(n=206)$ tinham ensino superior incompleto. O percentual de participantes que trabalhavam em empresas de grande porte (acima de 500 funcionários) foi de 59,2\% ( $n=189)$. Quanto às chefias imediatas, a faixa etária predominante ficou entre 31 e 40 anos (33,5\%; $n=113)$, sendo que $52,8 \%(n=178)$ eram do sexo masculino.

\section{Instrumentos}

Utilizou-se um questionário sociodemográfico e laboral que abordava questões sobre sexo, idade, escolaridade, ramo de atividade da empresa, em qual setor trabalhava, renda individual, tempo de empresa e de trabalho com a chefia, além do sexo e faixa etária do chefe. Ademais, três instrumentos foram utilizados:

1. Servant Leadership Questionnaire (SLQ - avaliadores), versão traduzida e adaptada neste estudo. O instrumento, construído por Barbuto e Wheeler (2006), mensura o nível de concordância com os comportamentos expressados pela chefia. Possui quatro pontos, variando entre 1 (Discordo totalmente) e 4 (Concordo 
totalmente) e apresenta cinco dimensões: vocação altruísta ( $\alpha=0,82 ; 4$ itens), o desejo de servir e disposição de se sacrificar para o benefício dos colaboradores; cura emocional ( $\alpha=0,91 ; 4$ itens), a capacidade de reconhecer quando e como deve-se promover o processo de suporte emocional; sabedoria ( $\alpha=0,92 ; 5$ itens), a astúcia do líder para observar pistas no ambiente de trabalho e tomar providências a fim de manter a ordem e a evolução dos processos; mapeamento persuasivo ( $\alpha=0,87 ; 5$ itens), a capacidade de influenciar e persuadir os demais, desconsiderando a autoridade formal; e intendência organizacional ( $\alpha=0,89 ; 5$ itens), que envolve a administração da organização, gerando confiança aos seus membros para contribuições em prol da sociedade.

2. Escala de Atitudes frente a Estilos de Liderança, bidimensional, contendo comportamentos frente à liderança transformacional ( $\alpha=0,91 ; 24$ itens) e à liderança transacional ( $\alpha=0,74 ; 8$ itens). Tal instrumento, proposto por Fonseca e Porto (2013) no intuito de indicar a favorabilidade quanto ao comportamento do líder, possui sete pontos, variando entre -3 (Totalmente contrário) e 3 (Totalmente favorável).

3. Escala de Satisfação no Trabalho (EST - forma reduzida), construída por Siqueira (2008) para investigar o nível de satisfação no trabalho, possui cinco dimensões (variando entre 1 - Totalmente insatisfeito e 7 Totalmente satisfeito): satisfação com o salário ( $\alpha=0,90 ; 3$ itens); satisfação com os colegas de trabalho ( $\alpha=0,81$; 3 itens); satisfação com a chefia ( $\alpha=0,84 ; 3$ itens); satisfação com as promoções ( $\alpha=0,81 ; 3$ itens); e satisfação com a natureza do trabalho ( $\alpha=0,77 ; 3$ itens).

\section{Procedimentos de coleta de dados e cuidados éticos}

Em conformidade com as normas do Conselho Nacional de Saúde, cuidados éticos para pesquisas com seres humanos foram empregados. Os participantes foram abordados na instituição de ensino, sendo que os alunos eram convidados prioritariamente em momentos em que não estavam em atividade acadêmica. Houve também a abordagem em sala de aula, e, quanto aos funcionários, a abordagem ocorreu em seus próprios ambientes de trabalho.

Todos que aceitaram participar declararam se encaixar nos critérios de inclusão da pesquisa e deram seu consentimento no Termo de Consentimento Livre e Esclarecido. Em seguida, responderam aos instrumentos, levando em torno de 20 minutos. Vale ressaltar que, para a execução da pesquisa, foi concedida a permissão do primeiro autor do instrumento.

Buscando obter um instrumento válido para a utilização no Brasil, recorreu-se ao processo de adaptação, com as seguintes etapas: (a) tradução do instrumento do idioma de origem para o idioma-alvo, (b) síntese das versões traduzidas, (c) tradução reversa, (d) avaliação da síntese por experts e (e) avaliação do instrumento pelo público-alvo (Borsa, Damásio, \& Bandeira, 2012; Cassepp-Borges, Balbinotti, \& Teodoro, 2010).

Em seguida, na validação, os passos seguidos foram: (a) análise de pressupostos, (b) uso de medidas para confirmar a fatorabilidade dos dados, (c) escolha da análise e do método de extração, (d) interpretação dos fatores, (e) testes de confiabilidade, (f) validade convergente e (g) validade preditiva (Borsa et al., 2012; Field, 2009; Laros, 2005; Tabachnick \& Fidell, 2007).

\section{Procedimentos de análise de dados}

Os dados foram analisados no programa SPSS (Statistical Package for the Social Sciences), versão 19.0, utilizado para a criação do banco e inicialmente para a análise de pressupostos (visando solucionar erros de digitação, missings - valores omissos - e normalidade). Realizaram-se análises a fim de obter resultados descritivos (médias, desvio-padrão e frequências) com relação aos dados sociodemográficos, à EST, à Escala de Atitudes frente a Estilos de Liderança e à ELSE (neste caso, após a Análise Fatorial Exploratória - PAF). Para fins inferenciais, utilizou-se a: (a) PAF (fatoramento do eixo principal com rotação Promax); (b) a análise de confiabilidade, modelo alpha, a fim de atestar os índices psicométricos da ELSE; (c) correlação de Pearson, para realizar a validade convergente entre a ELSE e a Escala de Atitudes frente a Estilos de Liderança; e (d) Regressão linear (stepwise) para obter a validade preditiva da ELSE com o fator Satisfação com a chefia, do EST.

\section{RESULTADOS}

\section{Adaptação da ELSE}

Inicialmente, procedeu-se a tradução do SLQ do inglês americano para o português do Brasil por três brasileiros bilíngues, fluentes em inglês, sendo que dois eram especialistas com pós-graduação lato e strictu 
sensu na área e conheciam os objetivos do estudo. Os tradutores respeitaram a equivalência da tradução do questionário (equivalência do item), mantendo o significado da versão original. Assim, ao realizarem uma tradução rigorosa, não recorrendo apenas às dimensões lexicais, foram criadas três versões do instrumento. A partir da análise das traduções, criou-se a $1^{\mathrm{a}}$ versão da ELSE, em português. Posteriormente, procedeu-se a tradução reversa da $1^{\mathrm{a}}$ versão do instrumento, realizada por outros dois tradutores bilíngues, fluentes em inglês (um deles norte-americano), sem que tivessem um conhecimento prévio do questionário original. A partir das contribuições, manteve-se a $1^{\text {a }}$ versão da ELSE, visto que não foram encontradas divergências significativas.

Em seguida, a $1^{\mathrm{a}}$ versão foi submetida à comissão de experts, composta por cinco especialistas no construto e na cultura da população-alvo. Após a análise das respostas dos peritos, foi realizado ajuste no instrumento quanto à equivalência idiomática e conceitual, além do layout da instrução de preenchimento e dos itens, dando origem a $2^{a}$ versão da ELSE, em português. É importante frisar que nenhum item foi julgado como pertencente à dimensão diferente da indicada no instrumento original.

Posteriormente, a versão foi apresentada a seis pessoas representativas da população-alvo, colaborando ao especificar que o comportamento do líder servidor deveria ser voltado para atividades laborais, acrescentando-se tal informação ao final dos itens 3,13 e 21. Com isso, concluiu-se que o instrumento estava redigido de forma clara e concisa, e que sua estruturação permitia um correto preenchimento do questionário e sua consequente validação.

\section{Validação da ELSE}

Previamente à validação, foi feita a análise de pressupostos, que indicou missings em 17 dos 23 itens da escala, porém em percentual muito reduzido (dados substituídos pela média do respectivo item). A análise da distribuição dos 23 itens indicou índices satisfatórios quanto à normalidade, bem como a pouca incidência de outliers (dados distantes da média). Gráficos de dispersão por item revelaram que quatro itens precisavam ter a skewness (assimetria da distribuição) ajustada (procedimento realizado) e outros quatro itens a kurtosis (dispersão dos dados na distribuição). Além disso, não houve problema devido à ausência de linearidade.

A fim de confirmar a viabilidade do uso da análise fatorial para extrair fatores, utilizou-se a medida de adequação de Kaiser-Meyer-Olkin, que obteve valor de 0,934; o teste de esfericidade de Bartlett $\left[\chi^{2}(253)=3795,187\right.$; $p<0,001]$; e a média das comunalidades $(M=0,47)$, demonstrando que a correlação entre itens é adequada para a sua fatorabilidade. Considerando os métodos de extração de fatores, utilizou-se o critério de autovalor de Guttman-Kaiser, que acusou a fatoração com quatro componentes. No entanto, o teste gráfico screeplot revelou no máximo três componentes, decidindo-se que a melhor solução seria realmente com três fatores, pois eram coerentes com as recomendações psicométricas e devidamente interpretáveis.

Para auxiliar na estruturação e interpretação dos fatores encontrados, a rotação da matriz principal foi realizada para que cargas fatoriais pudessem ser destacadas em um único fator, organizando os itens de maneira compreensível. Para isso, realizou-se uma rotação oblíqua, pois os fatores eram teórica e empiricamente correlacionados, especificamente a rotação Promax, devido à grande correlação encontrada entre os três fatores do estudo. A solução definitiva apresentou três fatores, todos com eingenvalues maiores que 1, totalizando 47,7\% de variância explicada do instrumento. Os fatores encontrados, sua porcentagem de explicação da variância e os pesos de regressão dos itens encontram-se na Tabela 1. Ao avaliar a confiabilidade dos fatores, os índices foram adequados $(0,832$ a 0,879$)$. Ao analisar a contribuição dos itens para a consistência interna do fator à qual pertencem, foi constatado que todos os itens contribuem positivamente para o valor do alfa de Cronbach.

Seguindo o critério de englobar itens no fator em que sua carga fatorial fosse superior a 0,30, o fator 1 (38,3\% da variância), denominado influência visionária, associa-se à atenção, por parte do líder servidor, aos processos do trabalho e às relações, utilizando persuasão ao articular oportunidades para os subordinados. No fator 2 (6,7\% da variância), rotulado de abnegação, relaciona-se à busca do líder em servir aos subordinados, apresentando empatia ao lidar com problemas pessoais dos liderados. Já o fator 3 ( $2,7 \%$ da variância), denominado intendência organizacional, refere-se à administração da organização na busca de contribuir positivamente com a sociedade. 
TABELA 1. Análise Fatorial Exploratória (Fatoramento do Eixo Principal - rotação Promax) da ELSE

\begin{tabular}{|c|c|c|c|c|}
\hline \multirow{2}{*}{ Itens } & \multicolumn{3}{|c|}{ Cargas fatoriais } & \multirow{2}{*}{ Comunalidades $\left(\mathrm{h}^{2}\right)$} \\
\hline & 1 & 2 & 3 & \\
\hline Esta pessoa tem grande consciência do que está acontecendo no trabalho & 0,93 & & & 0,62 \\
\hline Esta pessoa parece sintonizada com o que está acontecendo no trabalho & 0,87 & & & 0,54 \\
\hline Esta pessoa parece prever o que vai acontecer no trabalho & 0,69 & & & 0,51 \\
\hline Esta pessoa é boa em me convencer a fazer as atividades do trabalho & 0,64 & & & 0,48 \\
\hline Esta pessoa parece sempre alerta ao que está acontecendo no trabalho & 0,62 & & & 0,36 \\
\hline Esta pessoa é boa em antecipar as consequências das decisões & 0,55 & & & 0,42 \\
\hline Esta pessoa é talentosa quando se trata de me convencer & 0,42 & & & 0,42 \\
\hline $\begin{array}{l}\text { Esta pessoa me oferece razões convincentes para que eu faça minhas ativi- } \\
\text { dades }\end{array}$ & 0,35 & & & 0,37 \\
\hline Esta pessoa é muito persuasiva & 0,35 & & & 0,26 \\
\hline Esta pessoa é talentosa em me ajudar emocionalmente & & 0,85 & & 0,70 \\
\hline Esta pessoa é uma das que poderia me ajudar a resolver meus ressentimentos & & 0,85 & & 0,53 \\
\hline Esta pessoa consegue me ajudar com minhas questões emocionais & & 0,80 & & 0,60 \\
\hline $\begin{array}{l}\text { Esta pessoa sacrifica seus próprios interesses para atender as minhas neces- } \\
\text { sidades }\end{array}$ & & 0,71 & & 0,44 \\
\hline Esta pessoa vai além da obrigação de atender às minhas necessidades & & 0,66 & & 0,52 \\
\hline $\begin{array}{l}\text { Esta pessoa é uma das que eu poderia contar se eu tivesse um problema } \\
\text { pessoal }\end{array}$ & & 0,55 & & 0,40 \\
\hline $\begin{array}{l}\text { Esta pessoa coloca meus principais interesses à frente dos próprios interesses } \\
\text { dela }\end{array}$ & & 0,52 & & 0,19 \\
\hline Esta pessoa faz tudo o que pode para me ajudar & & 0,35 & & 0,49 \\
\hline Esta pessoa me incentiva a sonhar alto em relação à organização & & 0,32 & & 0,44 \\
\hline $\begin{array}{l}\text { Esta pessoa acredita que a organização precisa ter um papel moral na socie- } \\
\text { dade }\end{array}$ & & & 0,86 & 0,44 \\
\hline $\begin{array}{l}\text { Esta pessoa avalia a organização pelo seu potencial de contribuir para a so- } \\
\text { ciedade }\end{array}$ & & & 0,69 & 0,56 \\
\hline $\begin{array}{l}\text { Esta pessoa está preparando a organização para fazer uma diferença positiva } \\
\text { no futuro da sociedade }\end{array}$ & & & 0,60 & 0,54 \\
\hline $\begin{array}{l}\text { Esta pessoa acredita que a nossa organização precisa funcionar como uma } \\
\text { comunidade }\end{array}$ & & & 0,58 & 0,47 \\
\hline Esta pessoa me encoraja a ter um espírito solidário no local de trabalho & & & 0,36 & 0,55 \\
\hline Número de itens & 9 & 9 & 5 & - \\
\hline Variância explicada & $38,3 \%$ & $6,7 \%$ & $2,7 \%$ & - \\
\hline Alfa de Cronbach $(\alpha)$ & 0,86 & 0,87 & 0,83 & - \\
\hline
\end{tabular}

Nota. Carga fatorial 1 = influência visionária; Carga fatorial 2 = abnegação; Carga fatorial 3 = intendência organizacional.

Considerando a composição dos cinco fatores da escala original (SLQ), a redução para três fatores unificou os itens de vocação altruísta e cura emocional, compondo a dimensão abnegação (incluído também um item de mapeamento persuasivo), e unificou os itens de sabedoria e mapeamento persuasivo, criando a influência visionária. O fator intendência organizacional permaneceu inalterado, inclusive com os mesmos itens da escala original.

As correlações entre os três fatores produzidos foram moderadas ou altas $(0,622$ e 0,723$)$, porém a unidimensionalidade da escala foi desconsiderada devido aos modelos teóricos e à possibilidade de interpretação do construto. Ao construir os fatores da liderança servidora, o que obteve maior média foi a intendência organizacional $(M=2,9 ; D P=0,76)$, seguido da influência visionária $(M=2,89 ; D P=0,63)$, e da abnegação $(M=2,2$; $D P=0,69)$. Ou seja, a amostra pesquisada concorda levemente que suas chefias apresentam comportamentos de intendência organizacional e influência visionária e discorda levemente em relação à abnegação.

\section{Validade convergente}

Com relação à Escala de Atitudes frente a Estilos de Liderança, que buscou avaliar a favorabilidade frente ao estilo de liderança transformacional e transacional, foi auferida média de 1,6 $(D P=1,04)$ para o primeiro estilo, enquanto que o segundo estilo alcançou 0,91 de média $(D P=1,07)$. $O$ instrumento varia entre os escores $-3 \mathrm{e}+3$, mostrando que tanto as atitudes frente ao estilo de liderança transformacional quanto ao estilo de liderança transacional são positivas, com preferência e maior destaque à liderança transformacional.

Ao realizar uma correlação de Pearson $(r)$ entre as três dimensões da ELSE e a liderança transformacional, da Escala de Atitudes frente a Estilos de Liderança, percebe-se que todas as correlações foram significativas e moderadas: (a) influência visionária $(r=0,467 ; p<0,001)$, (b) abnegação $(r=0,341 ; p<0,001)$ e (c) intendência 
organizacional $(r=0,435 ; p<0,001)$. Portanto, conclui-se que a liderança transformacional avalia fenômeno semelhante à liderança servidora, porém em níveis moderados, confirmando a validade convergente da ELSE.

\section{Validade preditiva}

Quanto às dimensões da satisfação com o trabalho, a que teve maior escore foi a satisfação com a chefia $(M=5,04 ; D P=1,28)$; seguida da satisfação com os colegas $(M=4,71 ; D P=1,26)$; satisfação com a natureza do trabalho $(M=4,38 ; D P=1,19)$; satisfação com o salário $(M=3,53 ; D P=1,64)$; e satisfação com as promoções $(M=3,25 ; D P=1,56)$. Considerando que a escala varia entre 1 e 7 , conclui-se que o nível da satisfação com a chefia $(M=5,04)$ é elevado, pois o escore ficou entre 5 e 7 pontos.

Para fins de validade preditiva, considerando o foco na liderança servidora, utilizou-se a satisfação com a chefia como variável dependente no modelo de regressão linear. Ao inserir as variáveis independentes uma de cada vez (método stepwise), observou-se que o melhor modelo preditivo era composto pelas três dimensões da ELSE, que obteve $48 \%$ da variância total explicada $\left(R^{2}=0,479 ; F=101,992 ; p<0,001\right)$, confirmando que as mesmas são boas preditoras da satisfação com a chefia. Constatou-se que todos os preditores foram significativos, com impactos positivos: (a) influência visionária $(\beta=0,349 ; t=5,79 ; p<0,001)$, (b) abnegação $(\beta=0,261 ; t=4,86$; $p<0,001)$ e (c) intendência organizacional $(\beta=0,175 ; t=2,878 ; p<0,04)$. Isso permite dizer que a influência visionária produz maior impacto na satisfação com a chefia do que as outras dimensões.

\section{DISCUSSÃO}

O objetivo de adaptar e validar o SLQ - avaliadores para uso no Brasil foi alcançado, com a criação da ELSE, oferecendo uma medida válida para desenvolver estudos sobre a liderança servidora. Estruturalmente, a ELSE se diferencia da SLQ na quantidade de dimensões, pois enquanto a última possui cinco fatores, o atual instrumento possui três fatores, o que traz implicações teóricas para o estudo da liderança servidora nacional e internacionalmente.

Até o momento, o construto foi discutido em raros estudos nacionais, que, em geral, buscaram discorrer teoricamente sobre a liderança servidora. Empiricamente, foram encontrados apenas um trabalho que buscou traduzir o instrumento Servant Leladership Assessment Instrument, de Dennis e Bocarnea (2005), aplicado a supervisores e instrutores de call center em Pernambuco (Costa, 2007), e o estudo de Luz (2011), em português, realizado com missionários moçambicanos.

Considerando a possibilidade de comparação com a amostra original a partir do processo de adaptação (Cassepp-Borges et al., 2010; Laros, 2005), buscou-se identificar na literatura instrumentos validados para mensurar a liderança servidora. Com isso, o SLQ de Barbuto e Wheeler (2006), foi escolhido para este estudo por voltar-se a trabalhadores em âmbito organizacional, estar baseado no principal modelo teórico da área (Spears, 1995), ter passado por validações convergente e preditiva no seu estudo original e sua estrutura fatorial e índices psicométricos estarem adequados (Tabachnick \& Fidell, 2007).

Quanto aos procedimentos utilizados na adaptação do SLQ buscou-se seguir o que é preconizado por Borsa et al. (2012) e Pasquali (2010), desde a tradução do instrumento por tradutores fluentes na língua original do SLQ e no idioma-alvo, passando por traduções reversas e a avaliação da comissão de experts, oferecendo considerações pertinentes ao instrumento final. Vale ressaltar que, para a compreensão da escala, se faz necessário a conclusão do ensino médio como escolaridade mínima.

Quanto às propriedades psicométricas da ELSE, os resultados obtidos foram satisfatórios. De acordo com Pasquali (2005) e Tabachnick e Fidell (2007), a confiabilidade situou-se bem acima do mínimo indicado para a validação de instrumentos $(0,70)$. Além disso, a variância explicada pelos três fatores foi de 47,7\%, com destaque para a influência visionária (38,3\%).

Com o intuito de interpretar as dimensões da ELSE, buscou-se a origem de cada um dos itens na SLQ para comparar com a atual estruturação. Das cinco dimensões do SLQ uma delas foi totalmente replicada nesta pesquisa: intendência organizacional. Ou seja, todos os cinco itens originais se agruparam neste fator, que versa sobre a administração da organização pelo líder servidor, gerando confiança aos seus membros ao agir em prol da sociedade (Barbuto \& Wheeler, 2006). A confiabilidade desta dimensão foi adequada (acima de 0,80).

$\mathrm{Na}$ literatura, a preocupação com o entorno da organização e as contribuições que podem ser oferecidas à sociedade são metas presentes do líder servidor. Spears (1995), por exemplo, exalta tal característica a partir da construção da comunidade, que seria o compromisso com a manutenção das relações entre organização e 
sociedade. Russel e Stone (2002) destacam uma dimensão chamada intendência, definida como a capacidade de gerenciar e desenvolver questões de outras pessoas a fim de contribuir para a comunidade. Com isso, constatou-se que a intendência organizacional representa bem as intenções e preocupações do líder servidor em contribuir tanto com a sua organização quanto com a sociedade, atuando como agente ativo, ético e inspirador para os subordinados.

Com relação aos itens que compõem a dimensão abnegação na ELSE, é possível observar a unificação de todos os elementos das dimensões vocação altruísta e cura emocional do SLQ além de um item da dimensão mapeamento persuasivo. A abnegação está associada à busca em servir aos subordinados, colocando as necessidades dos liderados acima dos seus próprios interesses, apresentando grande empatia e suporte para lidar com problemas pessoais e profissionais dos trabalhadores.

O fator congrega a principal característica do líder servidor, apresentada por Greenleaf (1970) e isso ocorre porque características como altruísmo e empatia são unificadas nesta dimensão. Em todos os modelos teóricos de liderança servidora, é possível encontrar uma dimensão associada à abnegação. Spears (1995), por exemplo, apresenta a empatia e a cura como características essenciais no suporte aos liderados. Patterson (2003) intitula uma das suas dimensões de serviço, entendida como uma missão que induz a aceitação da responsabilidade para com os outros por parte do líder servidor. Desse modo, a abnegação é uma dimensão que reflete, de modo claro, o comportamento altruísta do líder servidor.

O terceiro fator da ELSE, responsável pela maior parte da variância explicada do modelo, foi denominado influência visionária. Ele foi composto por nove itens associados à capacidade de antever os efeitos e repercussões, utilizando a persuasão e o convencimento para oferecer oportunidades aos subordinados. Os itens que compuseram a estrutura desse fator são originários das dimensões sabedoria e mapeamento persuasivo do SLQ. Com a influência visionária, demonstra-se que a liderança servidora, assim como a transformacional e a teoria da troca líder-membro, também preza pela capacidade de influência do líder, sendo que a visão de futuro, especificamente, é o fator norteador para o líder servidor.

Tal dimensão encontra respaldo em modelos teóricos como o de Patterson (2003) e o de Russel e Stone (2002), em que as características de servir ao próximo, oferecendo suporte emocional, e influenciar a partir da antecipação do que ocorrerá no futuro são apresentadas. Acredita-se que a influência visionária é uma característica típica do líder servidor, que busca convencer com base nas suas competências e não apenas pelo papel formal assumido.

Diante dos índices psicométricos apresentados e das conceituações das dimensões construídas da ELSE, é possível afirmar que a amostra deste estudo, formada por brasileiros, compreende a liderança servidora de maneira distinta da amostra americana, no estudo original. Quanto à dimensão intendência organizacional, percebe-se uma clara congruência entre as duas escalas, pois os mesmos itens foram replicados na amostra brasileira, o que destaca a compreensão similar quanto à noção do termo.

Já com relação à abnegação, percebe-se essencialmente a fusão da vocação altruísta com a cura emocional, do SLQ que denotam a não diferenciação por parte da amostra brasileira entre o ato de servir aos subordinados em primeiro lugar, ao mesmo tempo que o líder age com empatia e grande suporte emocional frente aos liderados. Outro ponto que pode embasar essa unificação é o fato das duas referidas dimensões do SLQ possuírem a maior correlação positiva $(r=0,71)$ no conjunto de fatores da escala original, o que demonstra uma grande proximidade entre elas na visão da própria amostra americana.

Quanto à influência visionária, houve também uma unificação de dimensões do SLQ (sabedoria e mapeamento persuasivo) por parte da interpretação proveniente da amostra brasileira, ocorrida provavelmente pela percepção indistinta de confiança e credibilidade passadas pelo líder servidor, no intuito de persuadir os subordinados sobre qual a melhor direção seguir. Essa associação tornou o fator influência visionária responsável pelo maior variância explicada do instrumento, oferecendo maior suporte a tal unificação.

Com a atual estruturação da ELSE, verifica-se que alguns fatores do modelo teórico de Spears (1995) são contemplados, pois a abnegação engloba conceitualmente ouvir, empatia e cura; a influência visionária engloba a consciência, persuasão, conceituação e previsão; e a intendência organizacional representa a intendência. Apenas dois fatores não estão contemplados: crescimento das pessoas e construção da comunidade, devido ao fato do SLQ a partir dos procedimentos psicométricos utilizados para construí-lo, não incluir tais fatores. Vale ressaltar que mesmo não totalmente contemplada, a dimensão teórica construção da comunidade pode ser vista na dimensão empírica intendência organizacional, devido à definição desta e a formulação dos itens. 
Quanto à validade convergente, foram constatadas correlações significativas e moderadas na relação entre as dimensões da liderança servidora e a liderança transformadora, ratificando a convergência entre as escalas, tal como visto em outros estudos de validação da liderança servidora (Barbuto \& Wheeler, 2006; Ehrhart, 2004; Liden et al., 2008). Tal resultado pode ser explicado, segundo Barbuto e Wheeler (2006), pelos resultados esperados das duas tipologias e pela atuação a nível grupal. Mesmo a atuação do líder servidor sendo mais voltada para o desenvolvimento moral e a busca de autonomia dos seguidores, as duas tipologias se assemelham pelo fato do líder ser tomado como exemplo a ser seguido (Choudhary et al., 2013; Page \& Wong, 2000).

A validação convergente é uma análise importante quando se fala em validação de construto, pois ela apresenta um caráter confirmatório. De acordo com Malhotra (2012), ao indicar até onde a escala se correlaciona positivamente com outras medidas de um construto mais geral, a validade convergente situa adequadamente a nova medida elaborada no conjunto de outras já existentes, o que comprova a relevância do resultado encontrado neste estudo.

A partir da regressão linear, foi possível constatar a validade preditiva das dimensões da ELSE, que atuaram como antecedentes da satisfação com a chefia. O resultado encontrado corrobora diversos estudos da área que relacionam a liderança como preditora da satisfação no trabalho (Avolio et al., 2009; House \& Aditya, 1997), e, especificamente, a liderança servidora (Barbuto \& Wheeler, 2006; Choudhary et al., 2013; Ehrhart, 2004; Van Dierendonck, 2011).

O comportamento do líder servidor no auxílio aos subordinados a alcançarem seus objetivos denota a preocupação em atingir as metas dos mesmos. Esse suporte emocional, em conjunto com proposições dignas para o futuro dos seguidores, torna-os satisfeitos e, consequentemente, mais produtivos (Pousa, 2014; Siqueira, 2008). É importante frisar que alguns comportamentos aumentam a satisfação dos subordinados com relação aos seus chefes, como: a integridade, que seria a congruência entre o que é dito e o que é feito (Russel \& Stone, 2002), a empatia, que é a capacidade de entender e se colocar no lugar do outro, e o compromisso com o crescimento pessoal e profissional das pessoas (Spears, 1995). É importante destacar que, nas medidas empíricas de liderança servidora, os fatores quase sempre buscam retratar comportamentos que ampliem o nível de satisfação do subordinado, como no caso deste estudo, em que a influência visionária foi o fator com maior impacto na satisfação dos subordinados.

Assim como a satisfação com a chefia, outros construtos podem ser utilizados a fim de atestar o poder preditivo e averiguar o impacto nos comportamentos do líder servidor. Por exemplo, o comprometimento organizacional (Morris, 2013), desempenho (Choudhary et al., 2013), efetividade em equipes de trabalho (Mahembe \& Engelbrecht, 2014), engajamento no trabalho (Villiers, 2015), criatividade e inovação (Yoshida, Sendjays, Hirst, \& Cooper, 2014), inteligência emocional (Barbuto, Gottfredson, \& Searle, 2014; Plessis, Wakelin, \& Nel, 2015) e comportamentos proativos (Hunter et al., 2013).

Quando se pesquisa na literatura adaptações realizadas a partir do SLQ encontram-se até o momento dois estudos sul-africanos, sendo que o de Dannhauser e Boshoff (2007) aplicou o SLQem uma amostra de 417 vendedores de carros e obteve uma estrutura unifatorial. Por outro lado, Mahembe e Engelbrecht (2014), que aplicaram o SLQ em uma amostra de 288 professores, conseguiram replicar as cinco dimensões originais. Tais constatações demonstram diferentes achados, que podem estar ligados a questões culturais (Mittal \& Dorfman, 2012) e ao público-alvo de cada estudo (Pousa, 2014).

Por fim, ao considerar o alcance do objetivo deste estudo, com alguns méritos em termos psicométricos, faz-se necessário destacar algumas limitações desta pesquisa como: (a) a ausência de grupos profissionais específicos como parâmetros de comparação e (b) o uso da amostragem não probabilística. Em relação à ausência de grupos profissionais que pudessem ser comparados, este estudo não ofereceu tal possibilidade por ter um foco voltado para a validação de medidas. Logo, tal limitação permite que os resultados aqui encontrados sejam utilizados com cautela na investigação de categorias profissionais.

Outra questão foi o uso da amostragem não probabilística no delineamento da pesquisa, o que não contribui para a extrapolação direta dos dados para a população-alvo. Ainda que tal limitação não venha a desacreditar as qualidades psicométricas aqui obtidas, neste momento em que a escala está sendo proposta, é necessário ter cuidados para aplicações da ELSE. Enfim, considerando que o foco de futuros estudos seja destacar os comportamentos de líder servidor em categorias profissionais, aconselha-se que a amostragem probabilística seja preterida, garantindo maior representatividade da população-alvo. 
Nesta linha de raciocínio, sugere-se para futuros estudos investigar a estrutura fatorial da ELSE a fim de comprovar as características psicométricas apresentadas pelo instrumento neste estudo. Indica-se utilizar a escala em outros tipos amostrais, inclusive com fins correlacionais, e realizar, por exemplo, uma Análise Fatorial Confirmatória, no intuito de encontrar as dimensões influência visionária, abnegação e intendência organizacional. Outra sugestão se refere à realização de estudos que busquem agregar os fatores crescimento das pessoas e construção da comunidade, pertencentes ao modelo teórico de Spears (1995), a fim de utilizar instrumentos que agreguem todas as dimensões do referido modelo.

Um ponto que contribuiria para a investigação da estrutura fatorial seria o maior número de participantes no intuito de realizar análises inferenciais mais refinadas. Isso favoreceria a descoberta de algumas variáveis sociodemográficas e laborais que atuariam como preditoras dos comportamentos do líder servidor, a partir de regressões múltiplas e modelagem de equações estruturais (MEE).

Sugere-se, finalmente, que investigações futuras com a ELSE sejam realizadas com trabalhadores de áreas específicas a fim de investigar se o fenômeno da liderança servidora se diferencia de acordo com o ramo de atividade que a amostra está inserida (p. ex., saúde, segurança, educação), visto que neste estudo houve predominância de trabalhadores da área da educação e a estrutura fatorial encontrada provavelmente está relacionada a esse aspecto.

\section{REFERÊNCIAS}

Avolio, B. J., Walumbwa, F. O., \& Weber, T. J. (2009). Leadership: Current theories, research, and future directions. Annual Review of Psychology, 60, 421-449. doi: 10.1146/annurev.psych.60.110707.163621.

Bambale, A. J., Shamsudin, F. M., \& Subramaniam, C. A. (2012). Servant leadership as employee-organization approach for performance of employee citizenship behaviors in the Nigeria's electric power sector. Journal of Marketing and Managemant, 3(1), 1-21.

Barbuto, J. E., Gottfredson, R., \& Searle, T. P. (2014). An examination of emotional intelligence as an antecedent of servant leadership. Journal of Leadership \& Organizational Studies, 21(3), 315-323. doi: 10.1177/1548051814531826.

Barbuto, J. E., \& Wheeler, D. W. (2006). Scale development and construct clarification of servant leadership. Group and Organizational Management, 31(3), 300-326. doi: 10.1177/1059601106287091.

Borsa, J. C., Damásio, B. F., \& Bandeira, D. R. (2012). Adaptação e validação de instrumentos psicológicos entre culturas: Algumas considerações. Paideia, 22(53), 423-432. doi: 10.1590/1982-43272253201314.

Bass, B. M. (1990). Bass \& stogdill's handbook of leardership: Theory, reasearch and managerial applications. New York: The Free Press.

Cassepp-Borges, V., Balbinotti, M. A. A., \& Teodoro, M. L. M. (2010). Tradução e validação de conteúdo: Uma proposta para a adaptação de instrumentos. In L. Pasquali (Org.), Instrumentação psicológica: Fundamentos e práticas (pp. 506-520). Porto Alegre: Artmed.

Chan, S. C. H., \& Mak, W. (2015). The impact of servant leadership and subordinates' organizational tenure on trust in leader and attitudes. Personnel Review, 43(2), 272-287. doi: 10.1108/PR-08-2011-0125.

Choudhary, A. I., Akhtar, S. A., \& Zaheer, A. (2013). Impact of transformational and servant leadership on organizational performance. Journal Business and Ethics, 116(2), 433-440. doi: 10.1007/s10551-012-1470-8.

Costa, M. G. D. (2007). Em busca de um modelo brasileiro de mentoria e liderança: O caso de uma organização de Call Center (Dissertação de mestrado). Recuperado de http://favip.edu.br/arquivos/462012171215.pdf

Dannhauser, Z., \& Boshoff, A. B. (2007). The relationships between servant leadership, trust, team commitment and demographic variables. International Journal of Leadership Studies, 2(2), 148-168.

Dennis, R. S., \& Bocarnea, M. (2005). Development of the servant leadership assessment instrument. Leadership and Organization Development Journal, 26(8), 600-615. doi: 10.1108/01437730510633692.

Diamante, S., \& Grahl, J. R. (2012). Tipos de liderança: Definições, objetivos e impactos. Revista dos Alunos de Administração, 1 , 59-80.

Ehrhart, M. G. (2004). Leadership and procedural justice climate as antecedents of unit-level organizational citizenship behavior. Personnel Psychology, 57(1), 61-94.

Field, A. (2009). Descobrindo a estatística usando o SPSS (2a ed.). Porto Alegre: Artmed. 
Fonseca, A. M. O., \& Porto, J. B. (2013). Validação fatorial de escala de atitudes frente a estilos de liderança. Avaliação Psicológica, 12(2), 157-166.

Germano, I. M. P., \& Sá, D. R. (2013). O discurso pastoral-gerencial em ‘O monge e o executivo'. Psicologia em Estudo, 18(1), 103-113. doi:10.1590/S1413-73722013000100011.

Greenleaf, R. K. (1970). The servant as a leader. Indianapolis: Greenleaf Center.

Greenleaf, R. K. (1977). Servant leadership: A journey into the nature of legitimate power and greatness. New York: Paulist Press.

Hayden, R. W. (2011). Greenleaf 's 'best test' of servant leadership: A multilevel analysis (Dissertação de mestrado). Recuperado de http://digitalcommons.unl.edu/cgi/viewcontent.cgi?article=1029\&context=aglecdiss

House, R. J., \& Aditya, R. N. (1997). The social scientific study of leadership: Quo vadis? Journal of Management, 23(3), 409-473. doi: $10.1177 / 014920639702300306$

Hunter, E. M., Neubert, M. J., Perry, S. J., Witt, L. A., Penney, L. M., \& Weinberger, E. (2013). Servant leaders inspire servant followers: Antecedents and outcomes for employees and the organization. The Leadership Quarterly, 24(2), 316-331.

Laros, J. A. (2005). O uso da análise fatorial: Algumas diretrizes para pesquisadores. In L. Pasquali (Org.), Análise fatorial para pesquisadores (pp. 163-184). Brasília: INEP, MEC.

Laub, J. A. (1999). Assessing the servant organization: Development of the Organizational Leadership Assessment (OLA) model. Dissertation Abstracts International, 60(2), 1-115.

Liden, R. C., Wayne, S. J., Zhao, H., \& Henderson, D. (2008). Servant leadership: Development of a multidimensional measure and multi-level assessment. Leadership Quarterly, 19(2), 161-177.

Luz, L. P. (2011). Liderança servidora de expatriados: Validação de uma escala em organizações missionárias (Dissertação de mestrado). Recuperado de http://www.fumec.br/anexos/cursos/mestrado/dissertacoes/completa/leonardo_paulino_luz.pdf

Mahembe, B., \& Engelbrecht, A. S. (2014). The relationship between servant leadership, organisational citizenship behaviour and team affectiveness. SA Journal of Industrial Psychology, 4O(1), 1107-1117. doi: 10.4102/ sajip.v40i1.1107

Malhotra, N. (2012). Pesquisa de marketing: Uma orientação aplicada (6a ed.). Porto Alegre: Bookman.

Martins, E. C. B., Rosa, A. T. R. O., Silva, I. M. B. P., \& Bustos, L. C. S. (2012). Liderança servidora: O modelo Southwest Airlines. Revista de Ciência Gerenciais, 16(24), 189-202.

Mittal, R., \& Dorfman, P. W. (2012). Servant leadership across cultures. Journal of World Business, 47(4), 555-570. doi:10.1016/j. jwb.2012.01.009.

Morris, K. E. (2013). The effect of servant leadership on the organizational commitment of junior naval officers (Tese de doutorado). Recuperado de http://www.tntemple.edu/application/files/Academics/DMin/K.Morris.pdf

Page, D., \& Wong, P. T. P. (2000). A conceptual framework for measuring servant leadership. In S. Adjibolosoo (Org.), The human factor in shaping the course of history and development (pp. 434-456). Boston: University Press of America.

Pasquali, L. (1999). Testes referentes a construto: Teoria e modelo de construção. In L. Pasquali (Org.), Instrumentos psicológicos: Manual prático de elaboração (pp. 37-71). Brasília: LabPAM.

Pasquali, L. (2005). Teoria de resposta ao item - TRI: Manual para iniciantes. Brasília: INEP.

Pasquali, L. (2010). Instrumentação psicológica: Fundamentos e práticas. Porto Alegre: Artmed.

Patterson, K. A. (2003). Servant leadership: A theoretical model (Tese de doutorado). Recuperado de https://www.researchgate. net/publication/35237487_Servant_Leadership_A_Theoretical_Model

Plessis, M., Wakelin, Z., \& Nel, P. (2015). The influence of emotional intelligence and trust on servant leadership. SA Journal of Industrial Psychology, 41(1), 1133-1142. doi: 10.4102/sajip.v41i1.1133.

Pousa, C. (2014). Measuring servant leadership. In R. Selladurai \& S. Carraher (Orgs.), Servant Leadership: Research and Practice (pp. 211-243). Dallas: IGI Global.

Russell, R. F., \& Stone, A. G. (2002). A review of servant leadership attributes: Developing a practical model. Leadership and Organization Development Journal, 23(3), 145-157.

Siqueira, M. M. M. (2008). Satisfação no trabalho. In M. M. M. Siqueira (Org.), Medidas do comportamento organizacional: Ferramentas de diagnóstico e de gestão (pp. 257-266). Porto Alegre: Artmed.

Spears, L. C. (1995). Reflections on leadership: How Robert K. Greenleaf's theory of servant leadership influenced today's top management thinkers. New York: John Wiley. 
Spears, L. C. (2010). Character and servant leadership: Ten characteristics of effective, caring leaders. The Journal of Virtues \& Leadership, 1(1), 25-30.

Tabachnick, B. G., \& Fidell, L. S. (2007). Using multivariate statistics (5a ed.). New York: Harper Collins.

Van Dierendonck, D. (2011). Servant leadership: A review and synthesis. Journal of Management, 37(4), 1228-1261. doi:10.1177/0149206310380462.

Viegas, I. G. (2009). Cuidados do terapeuta de grupo em gestalt-terapia: Limites entre a atuação terapêutica e o exercício da liderança servidora. IGT na Rede, 7(13), 383-422.

Villiers, D. (2015). Top management team members's perception of executive servant leadership and their work engagement: Impact of gender and ethnicity (Dissertação de mestrado). Recuperado de http://aut.researchgateway.ac.nz/ handle/10292/8735

Weiszflog, W. (2012). Michaelis moderno dicionário da língua portuguesa (6a ed.). São Paulo: Melhoramentos Ltda.

Yoshida, D. T., Sendjaya, S., Hirst, G., \& Cooper, B. (2014). Does servant leadership foster creativity and innovation? A multi-level mediation study of identification and prototypicality. Journal of Business Research, 67, 1395-1404. doi: doi.org/10.1016/j. jbusres.2013.08.013.

Yukl, G. A., \& Van Fleet, D. D. (1992). Theory and research and leadership in organizations. In M. D. Dunnete \& L. M. Houghs (Orgs.), Handbook of industrial and organizational psychology (pp. 147-197). Palo Alto: Consulting Psychologists Press. 